27

\title{
The cytokine receptor DR3 identifies and activates thymic NKT17 cells
}

\author{
Shunqun Luo ${ }^{1,2}$, Nurcin Liman ${ }^{1,2}$, Assiatu Crossman ${ }^{1}$, and Jung-Hyun Park ${ }^{1, *}$ \\ ${ }^{1}$ Experimental Immunology Branch, Center for Cancer Research, National Cancer Institute, NIH, \\ Bethesda, MD 20892; ${ }^{2}$ contributed equally
}

Running title: DR3 is a functional marker of thymic NKT17 cells

\author{
*Address to correspondence to: \\ Jung-Hyun Park \\ Experimental Immunology Branch \\ Center for Cancer Research, NCI, NIH \\ Building 10, Room 5B17 \\ 10 Center Dr., Bethesda, MD 20892 \\ E-mail: Parkhy@mail.nih.gov
}




\section{Abstract}

29 Invariant natural killer T $(i \mathrm{NKT})$ cells are thymus-generated T cells with innate-like

30 characteristics and effector function. Several functionally distinct $i$ NKT subsets have been

31 identified, but NKT17 is the only $i$ NKT subset that produces the proinflammatory cytokine

32 IL-17. NKT17 cells are generated in the thymus and then exported into the periphery to

33 populate lymphoid organs and barrier tissues, such as the lung, to provide critical support in

34 host defense. However, the molecular mechanisms that drive the thymic development and

35 subset-specific activation of NKT17 cells remain mostly unknown. Here, we identify the

36 cytokine receptor DR3, a member of the TNF receptor superfamily, being selectively

37 expressed on NKT17 cells but absent on all other thymic $i$ NKT subsets. We further

38 demonstrate that DR3 ligation leads to the in vivo activation of thymic NKT17 cells and

39 provides in vitro costimulatory effects upon $\alpha$-GalCer-stimulation. Thus, our study reports

40 the identification of a specific surface marker for thymic NKT17 cells that selectively

41 triggers their activation both in vivo and in vitro. These findings provide new insights for

42 deciphering the role and function of IL-17-producing NKT17 cells and for understanding the

43 development and activation mechanisms of $i$ NKT cells in general.

45 Keywords: CD138, IL-17, $i$ NKT cells, ROR $\gamma$ t, thymus. 


\section{Introduction}

$48 \quad i \mathrm{NKT}$ cells are thymus-derived effector T cells expressing a semi-invariant V $\alpha 14-\mathrm{J} \alpha 18 \mathrm{~T}$ cell receptor (TCR) that equips them with the ability to recognize microbial glycolipids in the context of the nonclassical MHC-I molecule CD1d. Unlike conventional $\alpha \beta$ T cells, $i$ NKT cells possess

51 the innate ability to express effector molecules and proinflammatory cytokines prior to their exposure to antigens. While $i$ NKT cells are few in their number and limited in their TCR repertoire, $i$ NKT cells play critical roles in immunosurveillance, inflammation, and host defense

54 (Bendelac et al., 2007; Crosby et al., 2018). There are several subsets of $i$ NKT cells, among which three major populations, i.e., NKT1, NKT2, and NKT17, have been identified (Lee et al., 2013). In particular, NKT17 cells are noted for their ability to produce the proinflammatory cytokine IL-17 and to express the transcription factor ROR $\gamma t$ (Lee et al., 2013). NKT17 cells can be identified by their distinct expression of the cell surface marker CD138 (Syndecan-1) (Dai et al., 2015). However, the role of CD138 in NKT17 cell biology remains mostly unclear (Dai et al., 2015)[Please add: Luo S., 2021, JCI Insight]. Because NKT17 cells are the major producers

61 of IL-17 in the thymus and in barrier tissues, such as the lung and skin (Tsagaratou, 2019), there

62 is a keen interest in delineating the developmental requirements and activation mechanism of

63 NKT17 cells. Here, we report the surprising finding that the TNF receptor superfamily member

64 Death Receptor-3 (DR3) is highly and specifically expressed on thymic NKT17 cells, and that

65 the stimulation of DR3 using agonistic anti-DR3 antibodies leads to the activation of NKT17

66 cells in the thymus, unveiling a new layer of control in NKT17 cell biology. 


\section{Results and Discussion}

The cytokine receptor DR3 is specifically expressed on thymic NKT17 cells

71 We embarked on this study to uncover new regulatory mechanisms and effector functions that

72 are specifically associated with individual $i$ NKT subsets, and particularly with NKT17 cells.

73 While CD138 is a specific marker for NKT17 cells, CD138 is not required for their generation or

74 effector function (Dai et al., 2015; Luo et al., 2021) Thus, functional markers for NKT17 cells

75 are currently not available. Because cytokines play critical roles in the generation and survival of

$i$ NKT cells (Bendelac et al., 2007; Crosby et al., 2018), we screened a panel of cytokine

receptors for their $i$ NKT subset-specific expression, and here we identified the TNF receptor

superfamily member 25 (TNFRS25), also known as DR3 (Meylan et al., 2011), being highly

expressed on thymic NKT17 cells (Figure 1A and 1B). As expected, DR3 expression correlated

(Figure 1A, 1B; Figure 1-figure supplement 1). On the other hand, DR3 expression was

ROR $\gamma \mathrm{t}$ (Ligons et al., 2018), the master transcription factor of NKT17 cell development and

expressing $i$ NKT cells (Figure 1D). These results suggested that DR3 expression is controlled

87 downstream of ROR $\gamma \mathrm{t}$ so that all $\mathrm{DR} 3^{+}$thymic $i \mathrm{NKT}$ cells of ROR $\gamma \mathrm{t}^{\mathrm{Tg}}$ mice also expressed

\section{CD138 (Figure 1D; Figure 1-figure supplement 2).}

Consistent with the notion that DR3 is highly expressed on Foxp $3^{+}$Treg cells (Nishikii et al.,

91 2016), the stimulation with TL1A or the ligation of DR3 with agonistic anti-DR3 antibodies 
92 triggers the activation of Foxp $3^{+}$Treg cells (Nishikii et al., 2016). Because we found NKT17

93 cells to express DR3, we thus asked whether DR3 ligation would also activate thymic NKT17

94 cells. To this end, we injected BALB/c mice with agonistic anti-DR3 antibodies and assessed

95 their effect on thymic $i$ NKT cells. Of note, we utilized BALB/c mice that were engineered to express Foxp3-GFP reporter proteins (Foxp3-DTR/EGFP mice) (Kim et al., 2007), which

97 allowed us to verify the in vivo effect of anti-DR3 injection. Indeed, assessing GFP-expressing

98 CD4 T cells confirmed that DR3 ligation induced the expansion of Foxp3 ${ }^{+}$Treg cells (Figure

2A). Curiously, while both the frequency and number of Foxp $3^{+}$cells were significantly

100 increased in DR3-injected mice, at the same time, the frequency and number of thymic NKT17 cells were dramatically diminished (Figure 2B). Thus, DR3 ligation clearly affected NKT17 cells, but DR3 activation appeared to be detrimental instead of stimulatory for thymic NKT17 cells.

Because we identified NKT17 cells based on their CD138 expression (Luo et al., 2021), we could not exclude the possibility that DR3 ligation would appear to deplete NKT17 cells by downregulating CD138 expression. In fact, the shedding of the CD138 ectodomain is a welldescribed process that results in the loss of surface CD138 (Rangarajan et al., 2020), so that DR3 ligation might have triggered CD138 downregulation without altering the composition of the thymic $i$ NKT cells. To determine whether DR3 ligation leads to the actual loss of NKT17 cells or if anti-DR3 only induces the downregulation of surface CD138 expression on NKT17

111 cells, we considered it necessary to identify NKT17 cells with markers other than surface

112 CD138. Hence, we employed the surface markers CD4 and CD122 to discriminate individual $113 i$ NKT subsets (Georgiev et al., 2016). CD122 is selectively expressed on NKT1 cells (Won et al., 1142021 ), so that CD122 $i$ NKT cells correspond to the NKT1 subset. NKT2 cells are CD122- 
115

116

117

118

119

120

121

122

123

124

125

126

127

128

129

130

131

132

133

134

135

negative but they express large amounts of CD4 $\left(\mathrm{CD} 122^{-} \mathrm{CD} 4^{+}\right)$. Most NKT17 cells, on the other hand, are negative for both CD4 and CD122 (Georgiev et al., 2016). In fact, CD122/CD4 double-negative (DN) cells were ROR $\gamma \mathrm{t}^{+}$and expressed high levels of both DR3 and CD138, confirming that they corresponded to NKT17 cells (Figure 3A). Therefore, the combined use of CD122 and CD4 permitted us to identify NKT17 subset cells without using CD138. In agreement, DR3 was also highly expressed on the DN $i$ NKT cells of CD138-deficient $S d c 1^{-/-}$ mice, marking them as NKT17 cells, (Figure 3B). These results indicated that DR3 expression is a bona fide marker for thymic NKT17 cells, independently of CD138.

\section{DR3 ligation selectively activates thymic NKT17 cells}

Equipped with this toolkit to identify NKT17 cells, we next assessed the effect of DR3 ligation on NKT17 cells. Injection of agonistic anti-DR3 antibodies into BALB/c mice induced the expression of CD69, a classical activation marker (Ziegler et al., 1994), on thymic NKT17 cells which was accompanied by decreased CD138 expression (Figure 3C). Consequently, the loss of

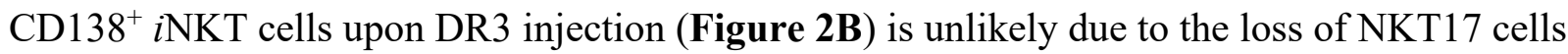
but more likely the result of their selective activation. Indeed, DR3-induced activation was largely limited to thymic NKT17 cells with minimal or no activation of NKT1 and NKT2 cells

(Figure 3C; Figure 3-figure supplement 1). Importantly, DR3 signaling was reported to require the co-expression of galectin-9 (Madireddi et al., 2017), and we found that NKT17 cells were incidentally the only thymic $i$ NKT subset that expressed both DR3 and galectin-9 (Figure

\section{D; Figure 3-figure supplement 2).}

While the injection of anti-DR3 antibodies activated NKT17 cells in vivo, anti-DR3 antibodies alone were insufficient to induce their activation in vitro (Figure 3E). However, DR3 
138 ligation significantly boosted the effect of $\alpha$-GalCer stimulation and bolstered the expression of

139 the activation markers CD25 and CD69 on NKT17 cells (Figure 3E; Figure 3-figure

140 supplement 3), indicating that DR3 acts as a costimulatory molecule. Altogether, these results

141 suggested that DR3 is a functional marker for NKT17 cells through which the $i$ NKT immune

142 response can be skewed towards IL-17 immunity. Finally, we examined whether CD138 is a

143 prerequisite for DR3-induced activation of CD138 for NKT17 cells (Dai et al., 2015). Here, we

144 found that $S d c 1^{-/-}$NKT17 cells still responded robustly to DR3 ligation so that the activation-

145 induced upregulation of CD69 was comparable to that of WT NKT17 cells (Figure 3F).

146 Therefore, CD138 is specifically expressed on NKT17 cells but not required for DR3-induced

147 NKT17 activation.

148 Collectively, our results identified the cytokine receptor DR3 as a new costimulatory

149 molecule that is specifically expressed on and activates thymic NKT17 cells. In this regard, DR3

150 represents a new class of immunomodulatory molecules whose expression and function are

151 linked to a specific $i$ NKT subset. These results open new avenues for elucidating how different

$152 i$ NKT subsets, that express the same invariant TCR and respond to the same agonistic glycolipid,

153 i.e., $\alpha$-GalCer, can elicit subset-specific immune responses in vivo.

155 Materials and Methods

157 Mice

$158 \mathrm{BALB} / \mathrm{cAnNCrl}$ and $\mathrm{C} 57 \mathrm{BL} / 6$ mice were purchased from the Charles River Laboratories.

159 CD138-deficient $\left(S d c 1^{-/-}\right)$mice and ROR $\gamma \mathrm{t}^{\mathrm{Tg}}$ mice were previously described (Alexander et al., 
BALB/cAnNCrl background before analyses. Foxp3-DTR/EGFP mice were obtained from the Jackson Laboratory and maintained on BALB/cAnNCrl background (Lahl et al., 2007). Animal experiments were approved by the NCI Animal Care and Use Committee. All mice were cared

164 for in accordance with the NIH guidelines.

Antibodies

167 Antibodies specific for the following antigens were used for staining: TCR $\beta$ (H57-597), CD4 (GK1.5), CD24 (M1/69), CD138 (181-2), CD122 (TM-ß1), CD44 (IM7), DR3 (4C12), Galectin9 (108A2), CD69 (H1.2F3), CD25 (PC61.5), IL-7R $\alpha$ (A7R34), IL-17 (eBio17B7), PLZF (9E12), and ROR $\gamma \mathrm{t}$ (Q31-378). Armenian Hamster IgG isotype Control Antibody (HTK888) was used as

171 control for anti-DR3 staining. Rat IgG2a, $\kappa$ Isotype Ctrl (RTK2758) was used as control for anti-

172 Galectin-9 staining. PBS-57-loaded mouse CD1d tetramers were obtained from NIH Tetramer 173 Core Facility (Emory University, Atlanta, GA).

\section{Enrichment of mature thymocytes}

176 CD24-negative mature thymocytes were enriched by magnetic depletion of $\mathrm{CD} 24^{+}$cells, as

177 previously described (Park,Kwon, et al., 2019). In brief, total thymocytes were processed to 178 single cell suspension in $10 \% \mathrm{FBS} / \mathrm{HBSS}\left(20 \times 10^{6}\right.$ cells $\left./ \mathrm{ml}\right)$ and incubated with rat anti-mouse 179 CD24 antibodies (M1/69, Biolegend) $\left(30 \mu \mathrm{g} / 100 \times 10^{6}\right.$ cells $)$ for 30 mins on ice. After washing 180 off excess reagents, thymocytes were mixed with anti-rat IgG-conjugated BioMag beads

181 (QIAgen) and incubated for 45 mins at $4^{\circ} \mathrm{C}$ on a MACSmix Tube Rotator (Miltenyi Biotec).

182 Anti-CD24 antibody-bound cells were then magnetically removed, and non-binding cells were 183 harvested for further experiments. 


\section{Flow cytometry}

Fluorescence antibody-stained single-cell suspensions were analyzed using LSRFortessa or LSRII flow cytometers (BD Biosciences). For live cell analysis, dead cells were excluded by adding propidium iodide before running the samples on flow cytometers. For fixed cell staining and analysis, cells were stained with Ghost Dye Violet 510 (Tonbo) for exclusion of dead cells, followed by surface staining and fixation with Foxp3 fixation buffer (eBioscience). Afterwards,

191 cells were permeabilized using reagents from the Foxp3 intracellular kit according to the manufacturer's instructions (eBioscience). Excess reagents were removed by extensive washing in FACS buffer $(0.5 \%$ BSA, $0.1 \%$ sodium azide in HBSS $)$ before analysis.

\section{Identification of iNKT subsets by intracellular staining}

196 Thymic $i$ NKT subsets were identified by staining for transcription factors as previously 197 described (Park,DiPalma, et al., 2019). In brief, thymocytes were stained with fluorescence198 conjugated PBS-57-loaded mouse CD1d tetramers, followed by antibody staining for other 199 surface markers for 40 minutes. After washing out excess reagents, cells were fixed in $150 \mu l$ of

200 a 1:3 mixture of concentrate/diluent working solution of the Foxp3 Fixation Buffer and further 201 diluted with $100 \mu 1$ FACS buffer. After 20 minutes at room temperature, cells were washed twice 202 with permeabilization buffer (eBioscience) before adding antibodies for transcription factor 203 staining. After 1 hour of incubation at room temperature, cells were washed, resuspended in 204 FACS buffer, and analyzed by flow cytometry. 
207 For in vivo anti-DR3 ligation, mice were injected i.p. with either $10 \mu \mathrm{g}$ anti-DR3 antibody

208 (4C12, Biolegend) or $10 \mu \mathrm{g}$ Armenian Hamster IgG control antibody (HTK888, Biolegend). One

209 week after injection, thymus and spleen were harvested for further analysis.

\section{In vitro stimulation of thymic $i \mathrm{NKT}$ cells}

212 Single cell suspension of freshly isolated thymocytes were plated into 24 -well plates at $2 \times 10^{6}$

213 cells $/ \mathrm{mL}$ with $100 \mathrm{ng} / \mathrm{mL}$ of $\alpha$-GalCer in the presence or absence of anti-DR3 antibody (2

$214 \mu \mathrm{g} / \mathrm{mL})$ or with anti-DR3 antibody alone $(10 \mu \mathrm{g} / \mathrm{mL})($ Schreiber et al., 2010). Cells were

215 cultured overnight at $37^{\circ} \mathrm{C}$ in a $7.5 \% \mathrm{CO}_{2}$ incubator before analysis by flow cytometry.

\section{Statistics}

218 Data are shown as the mean \pm SEM. Two-tailed Student's $t$-test was used to calculate P values. P

219 values of less than 0.05 were considered significant, where NS indicates not significant.

220 Statistical data were analyzed using the GraphPad Prism 8 software.

\section{Acknowledgement}

223 This study was supported by the Intramural Research Program of the US National Institutes of

224 Health, National Cancer Institute, Center for Cancer Research.

225

226 Authorship Contribution: SL and NL designed and performed the experiments, analyzed the

227 data, and contributed to the writing of the manuscript. AC performed experiments, analyzed the

228 data, and commented on the manuscript. JP conceived the project, analyzed the data, and wrote

229 the manuscript. 
bioRxiv preprint doi: https://doi.org/10.1101/2021.09.27.461992; this version posted September 28, 2021. The copyright holder for this preprint (which was not certified by peer review) is the author/funder. This article is a US Government work. It is not subject to copyright under 17 USC 105 and is also made available for use under a CCO license.

231 Conflict-of-interest disclosure: The authors declare no competing financial interests.

233 ORCID profiles: S.L., 0000-0002-5728-2112; N.L.,0000-0002-2910-1070; A.C.,0000-0001-

234 5746-0073; J.H.P., 0000-0002-9547-9055. 


\section{References}

Alexander CM, Reichsman F, Hinkes MT, Lincecum J, Becker KA, Cumberledge S, Bernfield M. (2000). Syndecan-1 is required for Wnt-1-induced mammary tumorigenesis in mice. Nat Genet, 25(3), 329-332. https://doi.org/10.1038/77108

Bendelac A, Savage PB, Teyton L. (2007). The biology of NKT cells. Annu Rev Immunol, 25, 297-336. https://doi.org/10.1146/annurev.immunol.25.022106.141711

Crosby CM, Kronenberg M. (2018). Tissue-specific functions of invariant natural killer T cells. Nat Rev Immunol, 18(9), 559-574. https://doi.org/10.1038/s41577-018-0034-2

Dai H, Rahman A, Saxena A, Jaiswal AK, Mohamood A, Ramirez L, Noel S, Rabb H, Jie C, Hamad AR. (2015). Syndecan-1 identifies and controls the frequency of IL-17-producing naive natural killer T (NKT17) cells in mice. Eur J Immunol, 45(11), 3045-3051. https://doi.org/10.1002/eji.201545532

Georgiev H, Ravens I, Benarafa C, Forster R, Bernhardt G. (2016). Distinct gene expression patterns correlate with developmental and functional traits of iNKT subsets. Nat Commun, 7, 13116. https://doi.org/10.1038/ncomms13116

Kim JM, Rasmussen JP, Rudensky AY. (2007). Regulatory T cells prevent catastrophic autoimmunity throughout the lifespan of mice. Nat Immunol, 8(2), 191-197. https://doi.org/10.1038/ni1428

Lahl K, Loddenkemper C, Drouin C, Freyer J, Arnason J, Eberl G, Hamann A, Wagner H, Huehn J, Sparwasser T. (2007). Selective depletion of Foxp3+ regulatory T cells induces a scurfy-like disease. J Exp Med, 204(1), 57-63. https://doi.org/10.1084/jem.20061852

Lee YJ, Holzapfel KL, Zhu J, Jameson SC, Hogquist KA. (2013). Steady-state production of IL4 modulates immunity in mouse strains and is determined by lineage diversity of iNKT cells. Nat Immunol, 14(11), 1146-1154. https://doi.org/10.1038/ni.2731

Ligons DL, Hwang S, Waickman AT, Park JY, Luckey MA, Park JH. (2018). RORgammat limits the amount of the cytokine receptor gammac through the prosurvival factor $\mathrm{Bcl}-\mathrm{xL}$ in developing thymocytes. Sci Signal, 11(545). https://doi.org/10.1126/scisignal.aam8939

Luo S, Kwon J, Crossman A, Park PW, Park JH. (2021). CD138 expression is a molecular signature but not a developmental requirement for RORgammat+ NKT17 cells. JCI Insight, 6(18). https://doi.org/10.1172/jci.insight.148038

Madireddi S, Eun SY, Mehta AK, Birta A, Zajonc DM, Niki T, Hirashima M, Podack ER, Schreiber TH, Croft M. (2017). Regulatory T Cell-Mediated Suppression of Inflammation Induced by DR3 Signaling Is Dependent on Galectin-9. J Immunol, 199(8), 2721-2728. https://doi.org/10.4049/jimmunol.1700575 
Meylan F, Richard AC, Siegel RM. (2011). TL1A and DR3, a TNF family ligand-receptor pair that promotes lymphocyte costimulation, mucosal hyperplasia, and autoimmune inflammation. Immunol Rev, 244(1), 188-196. https://doi.org/10.1111/j.1600065X.2011.01068.X

Nishikii H, Kim BS, Yokoyama Y, Chen Y, Baker J, Pierini A, Alvarez M, Mavers M, MaasBauer K, Pan Y, Chiba S, Negrin RS. (2016). DR3 signaling modulates the function of Foxp3+ regulatory T cells and the severity of acute graft-versus-host disease. Blood, 128(24), 2846-2858. https://doi.org/10.1182/blood-2016-06-723783

Park JY, DiPalma DT, Kwon J, Fink J, Park JH. (2019). Quantitative Difference in PLZF Protein Expression Determines iNKT Lineage Fate and Controls Innate CD8 T Cell Generation. Cell Rep, 27(9), 2548-2557 e2544. https://doi.org/10.1016/j.celrep.2019.05.012

Park JY, Kwon J, Kim EY, Fink J, Kim HK, Park JH. (2019). CD24(+) Cell Depletion Permits Effective Enrichment of Thymic iNKT Cells While Preserving Their Subset Composition. Immune Netw, 19(2), e14. https://doi.org/10.4110/in.2019.19.e14

Rangarajan S, Richter JR, Richter RP, Bandari SK, Tripathi K, Vlodavsky I, Sanderson RD. (2020). Heparanase-enhanced Shedding of Syndecan-1 and Its Role in Driving Disease Pathogenesis and Progression. J Histochem Cytochem, 68(12), 823-840. https://doi.org/10.1369/0022155420937087

Schreiber TH, Wolf D, Tsai MS, Chirinos J, Deyev VV, Gonzalez L, Malek TR, Levy RB, Podack ER. (2010). Therapeutic Treg expansion in mice by TNFRSF25 prevents allergic lung inflammation. J Clin Invest, 120(10), 3629-3640. https://doi.org/10.1172/JCI42933

Tsagaratou A. (2019). Unveiling the regulation of NKT17 cell differentiation and function. Mol Immunol, 105, 55-61. https://doi.org/10.1016/j.molimm.2018.11.013

Valatas V, Kolios G, Bamias G. (2019). TL1A (TNFSF15) and DR3 (TNFRSF25): A Costimulatory System of Cytokines With Diverse Functions in Gut Mucosal Immunity. Front Immunol, 10, 583. https://doi.org/10.3389/fimmu.2019.00583

Won HY, Kim HK, Crossman A, Awasthi P, Gress RE, Park JH. (2021). The Timing and Abundance of IL-2Rbeta (CD122) Expression Control Thymic iNKT Cell Generation and NKT1 Subset Differentiation. Front Immunol, 12, 642856. https://doi.org/10.3389/fimmu.2021.642856

Ziegler SF, Ramsdell F, Alderson MR. (1994). The activation antigen CD69. Stem Cells, 12(5), 456-465. https://doi.org/10.1002/stem.5530120502 


\section{Figure legend}

Figure 1. DR3 is specifically expressed on thymic NKT17 cells

A. $i$ NKT subsets were identified among the thymocytes of BALB/c mice by staining for the intracellular proteins ROR $\gamma \mathrm{t}$ and PLZF and measuring the subset-specific expression of DR3 and CD138. The data are representative of 2 independent experiments with a total $4 \mathrm{BALB} / \mathrm{c}$ mice. show the summary of 2 independent experiments with a total of at least 4 BALB/c mice. with a total $4 S d c 1^{-/-}$and 4 WT BALB/c mice.

D. Thymic $i \mathrm{NKT}$ cells of ROR $\gamma \mathrm{t}^{\mathrm{Tg}}$ and littermate control (WT) BALB/c thymocytes were assessed for surface DR3 and CD138 expression. The contour plot is representative (left), and

337 ROR $\gamma \mathrm{t}^{\mathrm{Tg}}$ and 6 WT mice. Statistical significance was determined by paired two-tailed Student's $338 t$-tests.

339 The following figure supplements are available for Figure 1:

340 Figure supplement 1. DR3 expression on thymic NKT17 cells of C57BL/6 mice.

341 Figure supplement 2. Thymic CD138 $i$ NKT cells in WT and ROR $\gamma \mathrm{t}^{\mathrm{Tg}} \mathrm{BALB} / \mathrm{c}$ mice.

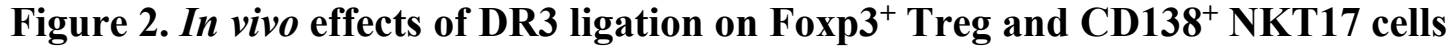


346 after 1 week of injection with anti-DR3 or isotype control antibodies into BALB/c Foxp3-GFP

347 reporter mice. The results are summarized from 4 independent experiments with a total of 4 mice

348 injected with anti-DR3 and 4 mice injected with isotype control. Statistical significance was

349 determined by paired two-tailed Student's $t$-tests.

B. Identification and enumeration of $\mathrm{CD} 138^{+}$thymic $i$ NKT cells among BALB/c Foxp3-GFP

reporter mice one week after injection of anti-DR3 or isotype control antibody (Ctrl IgG). The contour plot is representative, and the bar graphs are a summary of data from 11 independent experiments with a total of 11 mice for each group. Statistical significance was determined by paired two-tailed Student's $t$-tests.

\section{Figure 3. DR3 is a specific and functional marker of thymic NKT17 cells}

357 A. Thymic $i$ NKT subsets were identified by CD4 versus CD122 expression (contour plot), and the expression of subset-specific signature molecules were quantified for the indicated $i \mathrm{NKT}$ subsets (bar graphs). The contour plot is representative, and the bar graphs are summaries of data from three independent experiments with a total of $3 \mathrm{BALB} / \mathrm{c}$ mice. Statistical significance was

361 determined by unpaired two-tailed Student's $t$-tests. 
369 reporter mice injected either with anti-DR3 (7 mice) or isotype control antibodies (7 mice).

370 Statistical significance was determined by paired two-tailed Student's $t$-tests.

371 D. DR3 and Galectin-9 co-expression on thymic $i$ NKT subsets of BALB/c mice identified by the

372 CD4 versus CD122 expression. The graph is a summary of data from 2 independent experiments

373 with a total of $5 \mathrm{BALB} / \mathrm{c}$ mice.

374 E. In vitro activation of thymic NKT17 cells by overnight stimulation with $\alpha$-GalCer $(100 \mathrm{ng} / \mathrm{ml})$

375 in the presence or absence of anti-DR3 antibody $(2 \mu \mathrm{g} / \mathrm{ml})$ stimulation. The bar graph is a

376 summary of data from 4 independent experiments with a total of $10 \mathrm{BALB} / \mathrm{c}$ mice. Statistical

377 significance was determined by paired two-tailed Student's $t$-tests.

378 F. CD69 expression on thymic NKT17 cells from $S d c 1^{-1-}$ and littermate control (WT) BALB/c

379 mice one week after injection with anti-DR3 or isotype control antibodies (Ctrl IgG). The bar

380 graph is a summary of data from 4 independent experiments with a total of 4 mice for each

381 group. Statistical significance was determined by unpaired two-tailed Student's $t$-tests.

382 The following figure supplements are available for Figure 3:

383 Figure supplement 1. CD69 expression upon DR3 injection in thymic NKT1 and NKT2 cells.

384 Figure supplement 2. Galectin-9 and DR3 expression in thymic $i$ NKT cell subsets of BALB/c 385 mice.

386 Figure supplement 3. In vitro stimulation of thymic $i$ NKT cells with $\alpha$-GalCer and/or anti-DR3

387 antibodies. 


\section{Figure 1}

A
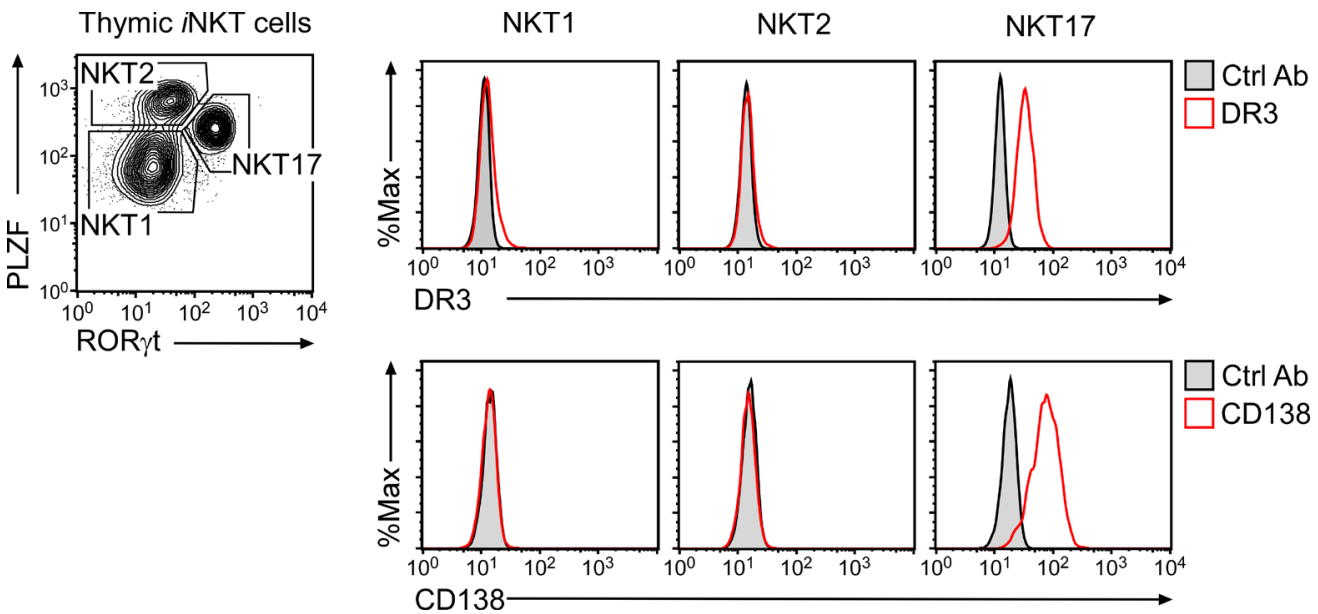

B
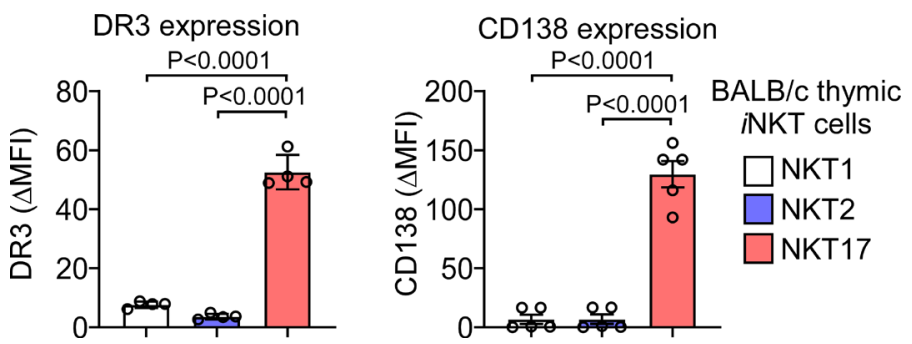

C

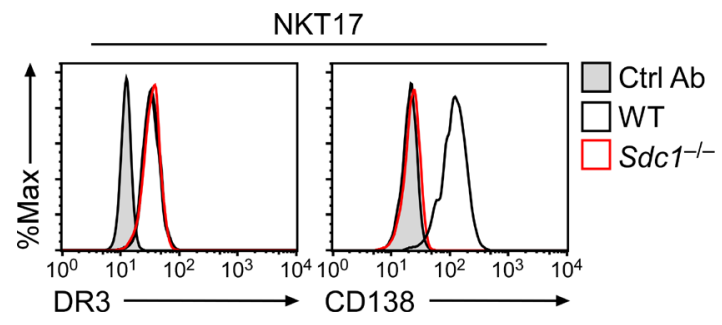

Thymic iNKT cells
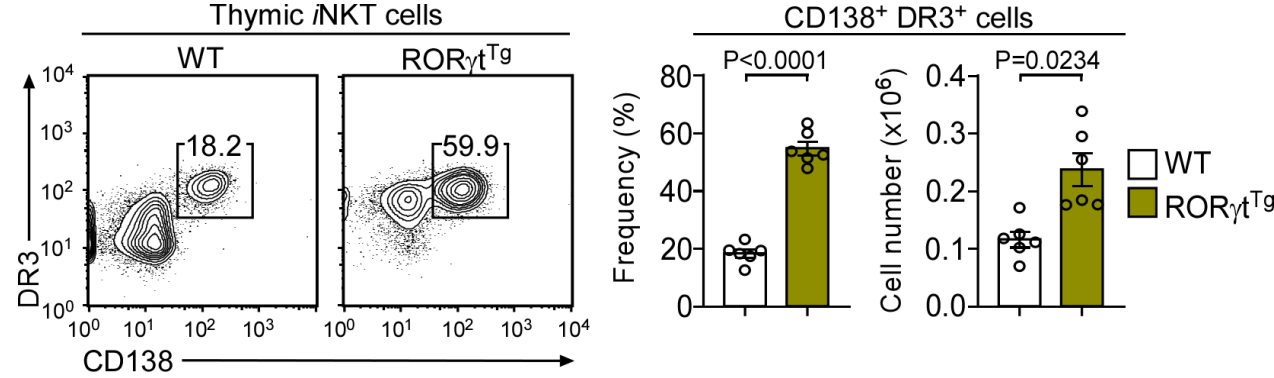
Figure 2

A
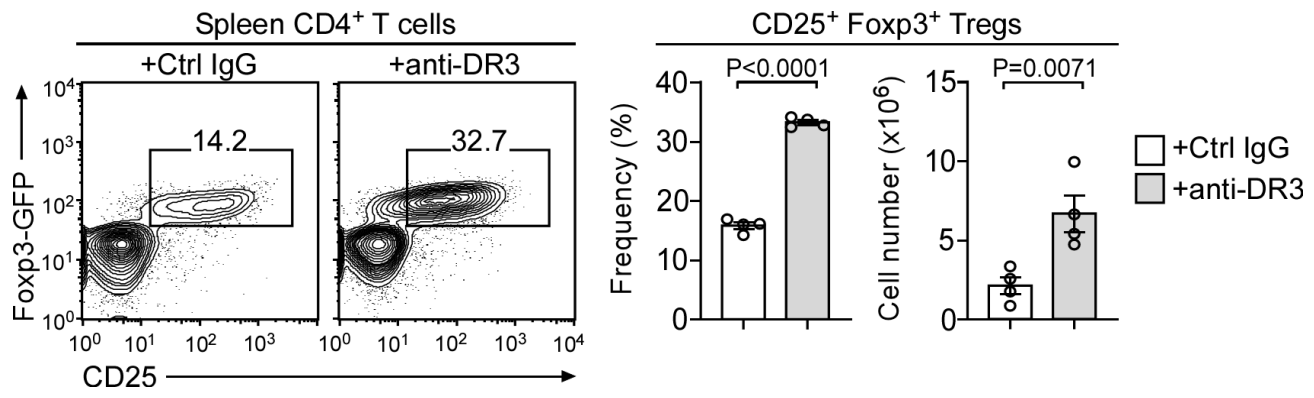

B

Thymic NKT cells

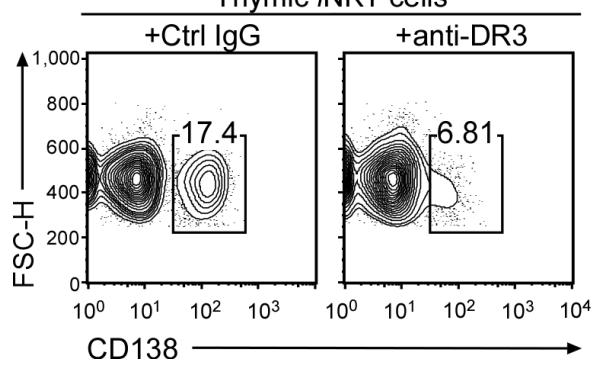

CD138 ${ }^{+}$cells

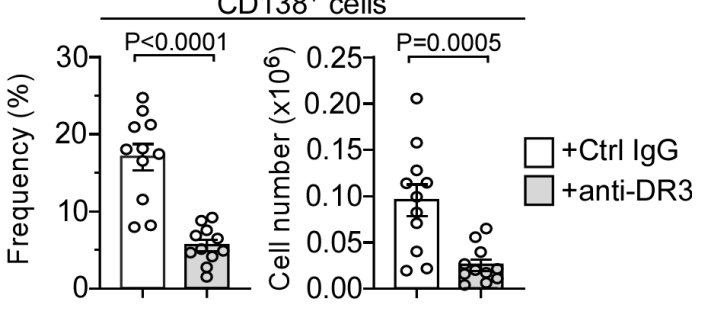




\section{Figure 3}

A

Thymic iNKT cells

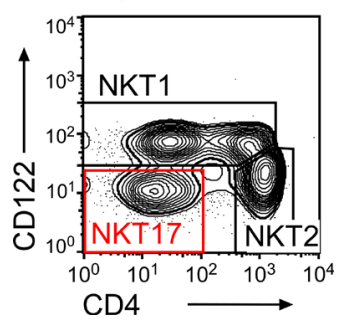

ROR $\gamma$ t expression $\mathrm{P}<0.0001$

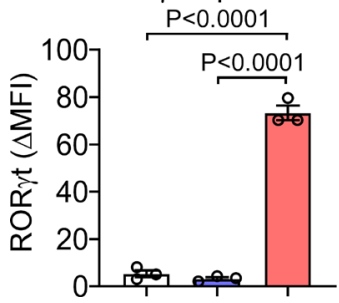

CD138 expression $\mathrm{P}<0.0001$

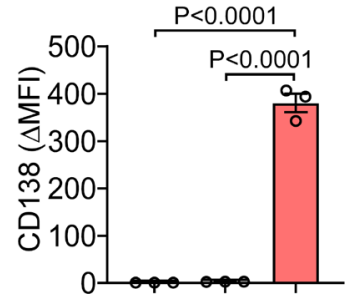

DR3 expression

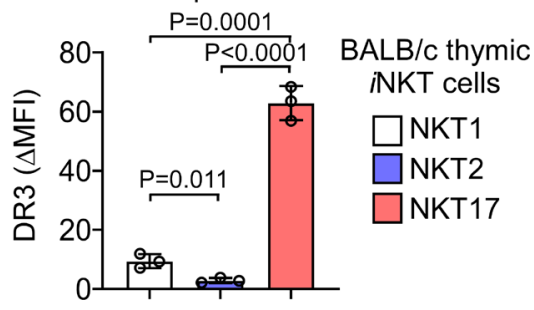

B

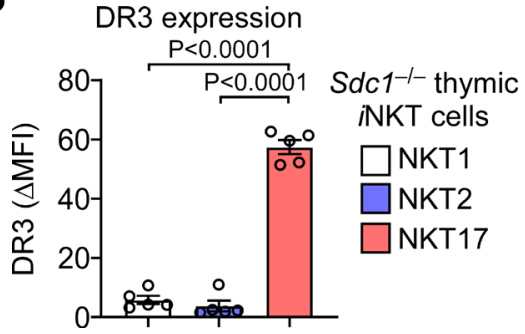

D

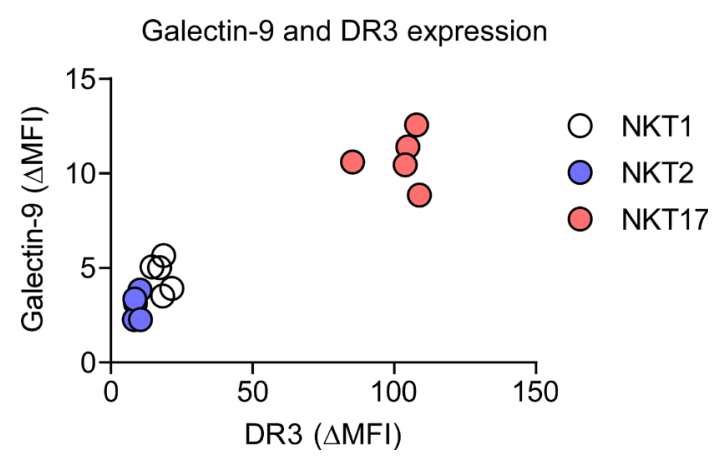

E

NKT17 cell activation

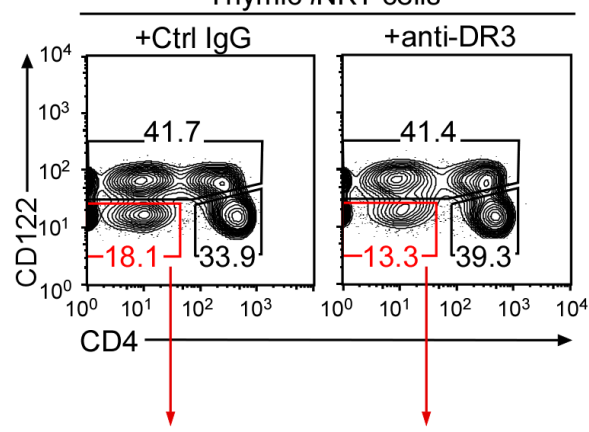

+ Ctrl lgG

NKT17 (DN)

+anti-DR3

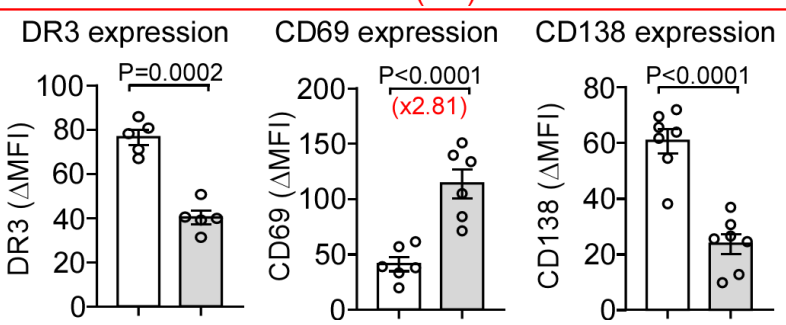

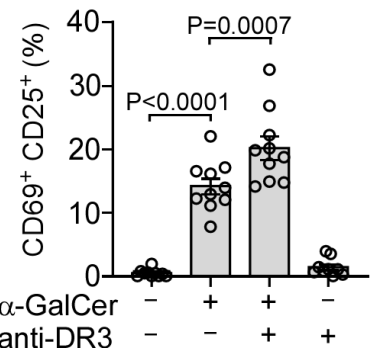

F

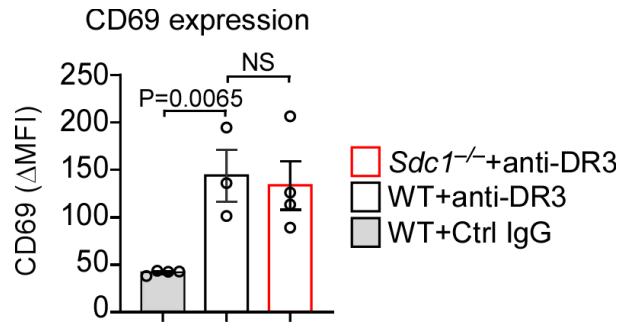




\section{Figure 1-figure supplement 1}

A
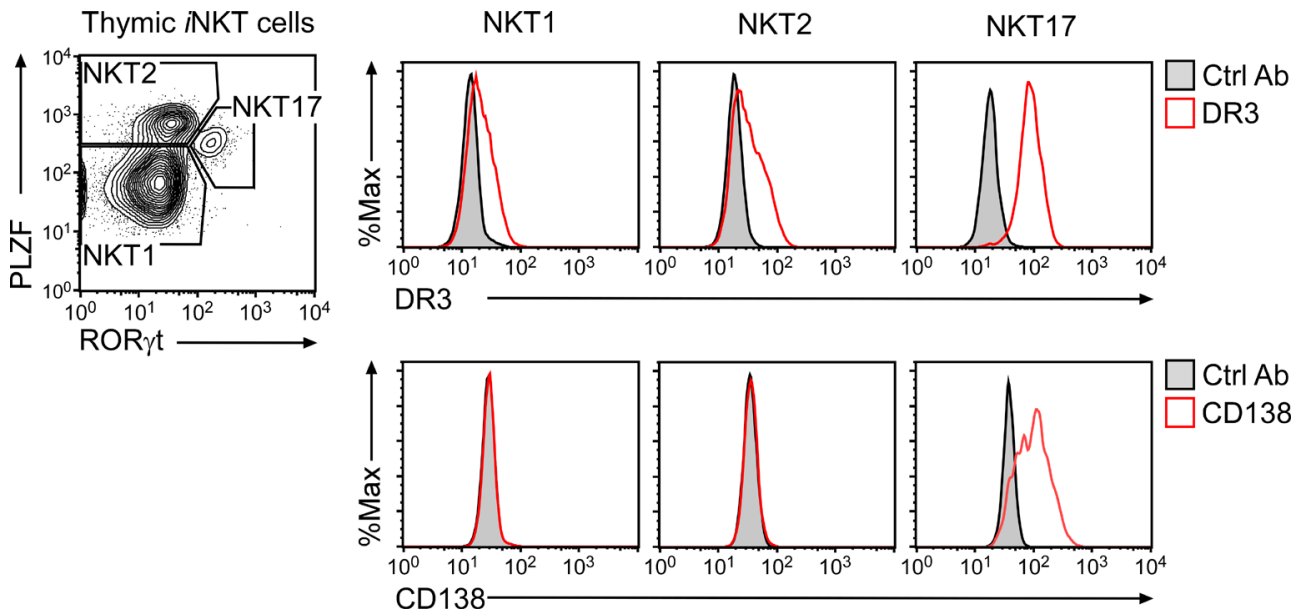

B
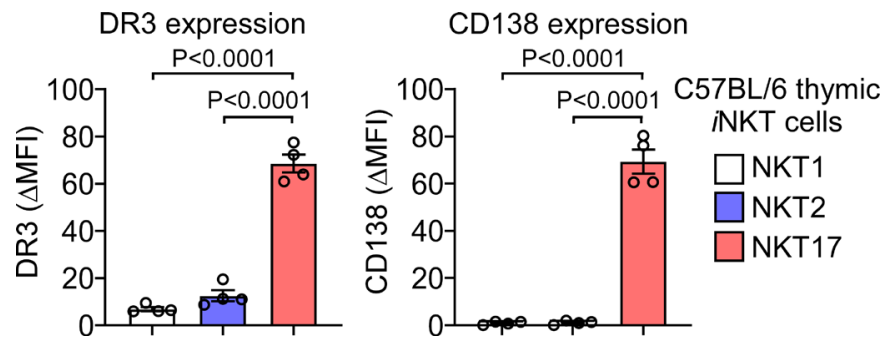

Figure 1-figure supplement 1. DR3 expression on thymic NKT17 cells of C57BL/6 mice A. $i$ NKT subsets were identified among thymocytes of C57BL/6 mice by intracellular staining for ROR $\gamma t$ and PLZF and assessed for subset-specific expression of DR3 and CD138. The data are representative of 3 independent experiments.

B. Bar graphs show DR3 expression ( $\triangle \mathrm{MFI}$ ) (left) and CD138 expression ( $\triangle \mathrm{MFI})$ (right) among thymic subsets of C57BL/6 mice as identified by intracellular staining for ROR $\gamma \mathrm{t}$ and PLZF. The data are from 3 independent experiments with a total of 4 pooled C57BL/6 mice and presented as mean \pm SEM. Statistical significance was determined by unpaired two-tailed Student's $t$-tests. 


\section{Figure 1-figure supplement 2}
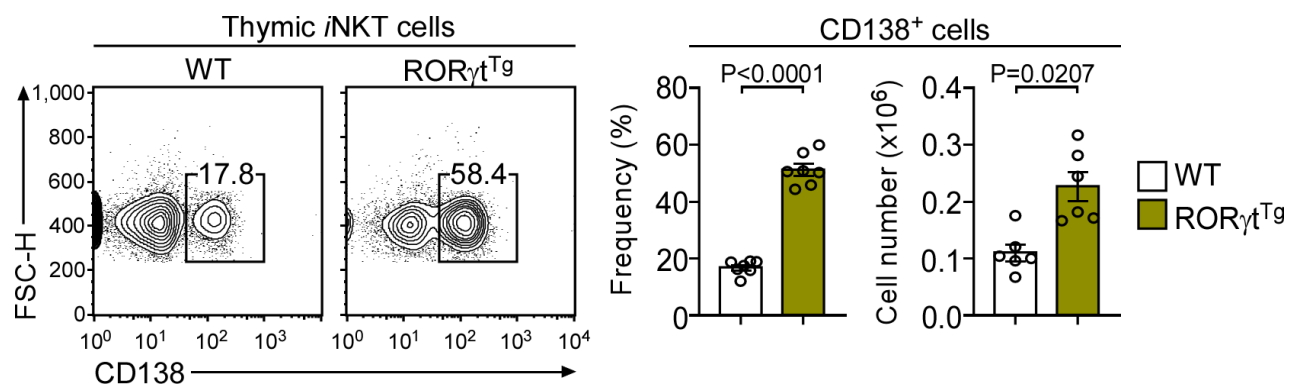

Figure 1-figure supplement 2. Thymic CD138 ${ }^{+} i N K T$ cells in WT and ROR $\gamma t^{\mathrm{Tg}}$ BALB/c mice Contour plots show CD138 versus FSC-H of $i$ NKT cells in littermate control (WT) BALB/c and $\mathrm{ROR} \gamma \mathrm{t}^{\mathrm{Tg}} \mathrm{BALB} / \mathrm{c}$ mice (left). Bar graphs show the frequency and cell number of CD138 $i \mathrm{NKT}$ cells in WT BALB/c and ROR $\gamma \mathrm{t}^{\mathrm{Tg}} \mathrm{BALB} / \mathrm{c}$ mice (right). Contour plots are representative and bar graphs show the summary of 3 independent experiments with a total of $6 \mathrm{WT}$ and $6 \mathrm{ROR} \gamma \mathrm{t}^{\mathrm{Tg}} \mathrm{BALB} / \mathrm{c}$ mice. Data are presented as mean \pm SEM. Statistical significance was determined by paired two-tailed Student's $t$-tests. 


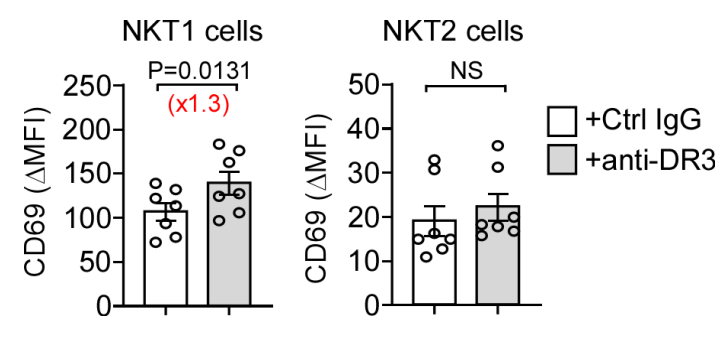

Figure 3-figure supplement 1. CD69 expression upon DR3 injection in thymic NKT1 and NKT2 cells

Bar graphs show the CD69 expression ( $\triangle \mathrm{MFI}$ ) of thymic NKT1 (left) and NKT2 (right) cells in Foxp3-DTR/EGFP BALB/c mice, one week after injection with anti-DR3 or isotype control antibodies. The results are summary of 7 independent experiments with a total of 14 mice injected with either anti-DR3 antibodies (7 mice) or with isotype control antibodies (7 mice). Data are presented as mean \pm SEM. NS, non-significant. Statistical significance was determined by paired two-tailed Student's $t$-tests. 


\section{Figure 3-figure supplement 2}

Thymic iNKT cells

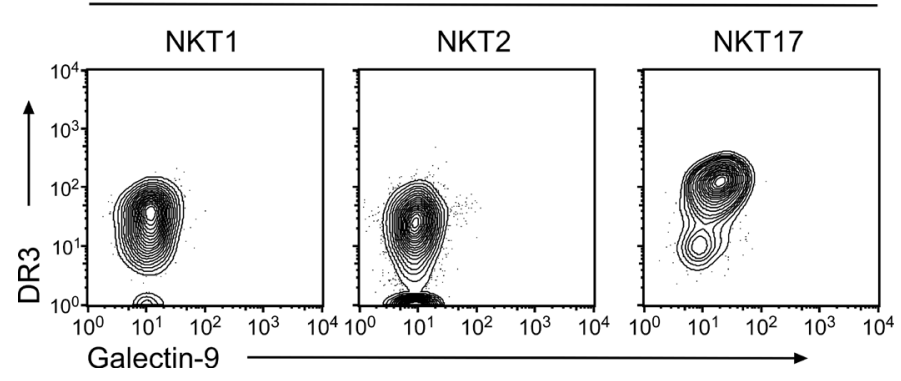

Figure 3-figure supplement 2. Galectin-9 and DR3 expression in thymic $i$ NKT cell subsets of BALB/c mice

The counter plots show galectin-9 versus DR3 profiles of thymic NKT1 cells (CD122 ${ }^{+}$), NKT2 cells $\left(\mathrm{CD} 122^{-} \mathrm{CD}^{+}\right)$and $\mathrm{NKT} 17$ cells $\left(\mathrm{CD} 122^{-} \mathrm{CD}^{-}\right)$. The data are representative of 2 independent experiments with a total of $5 \mathrm{WT}$ BALB/c mice. 


\section{Figure 3-figure supplement 3}

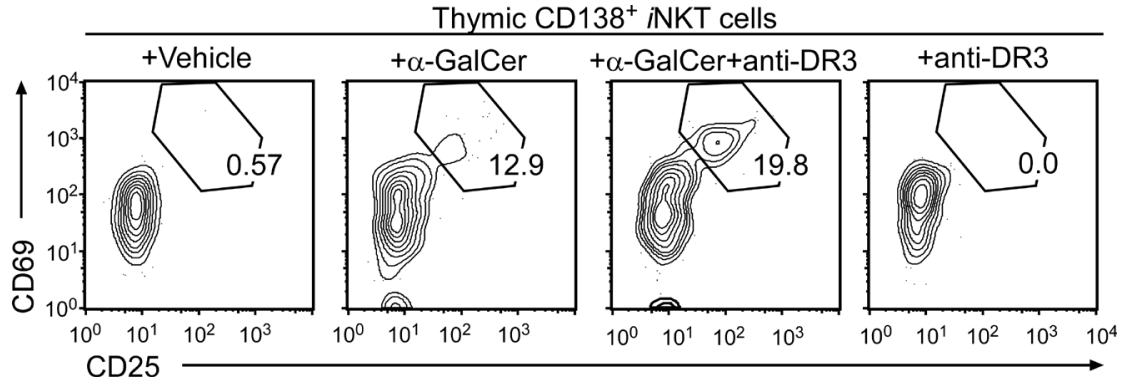

Figure 3-figure supplement 3. In vitro stimulation of thymic $i \mathrm{NKT}$ cells with $\alpha$-GalCer and/or anti-DR3 antibodies

Contour plots show CD69 versus CD25 profiles of CD138 thymic $i$ NKT cells of BALB/c mice that were cultured $\mathrm{O} / \mathrm{N}$ with $\alpha-G a l C e r$ and/or anti-DR3 antibodies. The data are representative of 4 independent experiments with a total of $10 \mathrm{WT} \mathrm{BALB/c}$ mice for each group. 